\title{
INSEMINAÇÃO ARTIFICIAL E INSEMINAÇÃO ARTIFICIAL EM
} TEMPO FIXO EM BOVINOS

\section{INSEMINACIÓN ARTIFICIAL E INSEMINACIÓN ARTIFICIAL A TIEMPO FIJO EN GANADO}

\section{ARTIFICIAL INSEMINATION AND TIMED ARTIFICIAL INSEMINATION IN CATTLE}

\begin{abstract}
Autor 1: Mery Any Nascimento da SILVA Graduação em Zootecnia Universidade Federal Rural do Rio de Janeiro - (UFRRJ), Seropédica - RJ - Brasil ORCID: https://orcid.org/0000-0002-2588-918X E-mail: meryany45@gmail.com

Autor 2: Marco Roberto Bourg de MELLO

Doutorado em Reprodução Animal (USP)

Professor Associado do Instituto de Zootecnia Universidade Federal Rural do Rio de Janeiro - (UFRRJ), Seropédica - RJ - Brasil

E-mail: mmrural@gmail.com

Autor 3: Helcimar Barbosa PALHANO

Doutorado em Ciências Veterinárias (UFRRJ)

Professor Associado do Instituto de Ciências Biológicas e da Saúde Universidade Federal Rural do Rio de Janeiro - (UFRRJ), Seropédica - RJ - Brasil ORCID: https://orcid.org/0000-0001-6109-2250 E-mail: helcimarpalhano@gmail.com
\end{abstract}


SILVA, M. A. N.; MELLO, M. R. B.; PALHANO, H. B. Inseminação artificial e inseminação artificial em tempo fixo em bovinos. R. Científica UBM - Barra Mansa (RJ), ano XXVI, v. 23, n. 45, 2 . Sem. 2021 p. $79-97$

ISSN 1516-4071

\section{RESUMO}

A presente revisão aborda aspectos históricos do uso da inseminação artificial (IA) como o início de uma nova era nas biotécnicas reprodutivas. No decorrer desta revisão, procurou-se relatar a evolução da IA no sentido de melhorar essa ferramenta de manejo reprodutivo com o advento da inseminação artificial em tempo fixo (IATF). São apresentadas as vantagens do uso dessas biotécnicas no manejo reprodutivo em bovinos de leite e corte, assim como algumas limitações, os ganhos em produtividade de leite e carne, a otimização do trabalho, ganhos genéticos e a contribuição sanitária no que diz respeito à prevenção de doenças da reprodução e daquelas que interferem na reprodução. Diante dos trabalhos apresentados, pode-se concluir que tanto a IA convencional como a IATF constituem ferramentas de manejo reprodutivo que ganham espaço crescente na bovinocultura por proporcionarem ganhos econômicos viáveis além possibilitar uma grande contribuição para organização e planejamento da atividade pecuária.

Palavras-Chave: Ciclo estral. Cio. Manejo reprodutivo. Ovulação. Sincronização.

\section{RESUMEN}

Esta revisión aborda los aspectos históricos del uso de la inseminación artificial (IA) como el comienzo de una nueva era en las biotecnologías reproductivas. Durante esta revisión, buscamos informar la evolución de la IA para mejorar esta herramienta de manejo reproductivo con el advenimiento de la inseminación artificial de tiempo fijo (FTAI). Se presentan las ventajas de utilizar estas biotecnologías en el manejo reproductivo del ganado lechero y de carne, así como algunas limitaciones, las ganancias en la productividad de la leche y la carne, la optimización del trabajo, las ganancias genéticas y el aporte a la salud en cuanto a la prevención de enfermedades de la reproducción y las que interfieren con la reproducción. A la vista de los trabajos presentados, se puede concluir que tanto la IA convencional como el IATF son herramientas de manejo reproductivo que están ganando cada vez más espacio en la ganadería ya que brindan ganancias económicas viables, además de hacer un gran aporte a la organización y planificación de la ganadería.

Palavras Clave: Ciclo estral. Celo. Manejo reproductivo. Ovulación. Sincronización.

\section{ABSTRACT}

The present review addresses historical aspects about artificial insemination (AI) as the beginning of a new era in reproductive biotechniques. In the course of this review, we attempted to report the evolution of $\mathrm{AI}$ in order to improve this reproductive management tool with the advent of timed artificial insemination (TAI). The advantages of the use of these biotechniques in the reproductive management of dairy and beef cattle, as well as some limitations, gains in milk and meat productivity, work optimization, genetic gains and the health contribution with respect to the prevention of reproductive disorders and those that interfere with reproduction. In view of the presented works, it is possible to conclude that both conventional AI and TAI are reproductive management tools that gain increasing space in cattle breeding because they provide viable economic gains besides making a great contribution to the organization and planning of the livestock activity. 
SILVA, M. A. N.; MELLO, M. R. B.; PALHANO, H. B. Inseminação artificial e inseminação artificial em tempo fixo em bovinos. R. Científica UBM - Barra Mansa (RJ), ano XXVI, v. 23, n. 45, 2 . Sem. 2021 p. 79-97 ISSN 1516-4071

Keywords: Estrous cycle. Heat. Reproductive management. Ovulation. Synchronization.

\section{INTRODUÇÃO}

O Brasil é o maior exportador de carne bovina do mundo, sendo essa produção uma das principais atividades que movimentam a economia brasileira. De acordo com o levantamento feito pelo IBGE (2016), o Brasil possuía um rebanho de 218,23 milhões de cabeças, atingindo a marca recorde no país. Novos levantamentos, realizados pelo IBGE em 2019, mostraram que no $1^{\circ}$ trimestre do mesmo ano foram abatidas 7,72 milhões de cabeças de bovinos sob algum tipo de serviço de inspeção sanitária e, também no $1^{\circ}$ trimestre de 2018 , a aquisição de leite cru, feita pelos estabelecimentos que atuam sob algum tipo de inspeção sanitária (federal, estadual ou municipal) atingiu 6 bilhões de litros, primeiro aumento depois de três anos de quedas consecutivas entre os primeiros trimestres.

Nesse contexto, a reprodução é um aspecto de grande relevância no conjunto de atividades da pecuária, seja ela norteada para produção de leite ou corte, sendo um fator que influencia, de forma direta e significativa, na lucratividade e nos indicadores de produção. Indicadores de eficiência reprodutiva aquém daqueles necessários para maximizar a produtividade estão relacionados a um aumento do período de anestro com consequente aumento do período de serviço e intervalo de partos (IP) devido ao manejo reprodutivo, nutricional e sanitário incorretos. Prolongado período de anestro em vacas de corte é uma das principais causas de perdas econômicas para os pecuaristas, por atrasar a concepção e/ou levar ao descarte por falha reprodutiva (MENEGHETTI; VASCONCELOS, 2008).

Segundo Palhano (2008), os principais prejuízos causados por um longo intervalo de partos são expressos por queda na produção de leite e diminuição do número de crias ao longo da vida produtiva da fêmea bovina. Portanto, para se obter um bom desempenho reprodutivo e, como consequência, um bom desempenho produtivo, deve-se atentar a todas as limitações existentes, na esfera reprodutiva, que possam prejudicar a taxa de prenhez, seja em pecuária de leite como de corte.

Dentre as limitações que impactam negativamente na performance reprodutiva, deve-se levar em consideração a relevância dos aspectos nutricionais e sanitários em que doenças da reprodução como brucelose, campilobacteriose e tricomonose genital bovina, assim como aquelas que interferem na reprodução, como leptospirose, rinotraqueíte infecciosa bovina (IBR) e diarreia viral bovina (BVD) que são responsáveis por grandes perdas reprodutivas por abortamento, absorção embrionária e repetição de cios impactando direta e negativamente na 
SILVA, M. A. N.; MELLO, M. R. B.; PALHANO, H. B. Inseminação artificial e inseminação artificial em tempo fixo em bovinos. R. Científica UBM - Barra Mansa (RJ), ano XXVI, v. 23, n. 45, 2 . Sem. 2021 p. 79-97 ISSN 1516-4071

taxa de concepção do rebanho, período de serviço e intervalo de partos, determinando ainda maiores custos operacionais com maiores gastos em doses de sêmen e medicamentos.

Neste sentido, a implantação de biotécnicas da reprodução em rebanhos de leite e corte, perpassa por um rigoroso monitoramento e controle de doenças infecciosas e parasitárias, manejo adequado, plano nutricional adequado ao modelo de produção, instalações apropriadas e escrituração zootécnica atualizada.

\section{DESENVOLVIMENTO}

\subsection{EVOLUÇÃO DA INSEMINAÇÃO ARTIFICIAL (IA) E DA INSEMINAÇÃO ARTIFICIAL EM TEMPO FIXO (IATF)}

Na primeira metade do século XX, a literatura especializada sobre reprodução animal e inseminação artificial era escassa no Brasil, ficando restrita a publicações em algumas poucas revistas agrícolas e em livros de zootecnia. Os responsáveis pelos primeiros trabalhos nacionais, publicados nessa área, foram médicos veterinários do Ministério da Agricultura e das Secretarias da Agricultura dos Estados da Federação. Os serviços de extensão rural ficavam a cargo dos órgãos oficiais que publicavam artigos e trabalhos em seus boletins técnicos (SEVERO, 2015).

Já na segunda metade do século XX, mais precisamente a partir da década de 1960, as universidades passaram a atuar na pesquisa científica da reprodução animal, incluindo a inseminação artificial como biotécnica reprodutiva. Nas últimas décadas do século XX, houve grande número de produções literárias sobre as biotécnicas de reprodução assistida no Brasil, isso se deve ao vasto volume de pesquisas desenvolvidas nas universidades e ao grande número de pesquisadores brasileiros associados a universidades e institutos de pesquisas.

A primeira referência brasileira sobre inseminação artificial foi publicada em abril de 1912, na revista de Veterinária e Zootecnia, e é de autoria do médico veterinário Epaminondas Alves de Souza. Nesse artigo, intitulado de "Inseminação Artificial", Souza sugere o uso da técnica em equinos e bovinos no país, citando os trabalhos norte-americanos realizados na estação de pesquisa de Oklahoma (RODRIGUES; RODRIGUES, 2009; SEVERO, 2015).

Posteriormente, o veterinário e professor Guilherme Hermsdorff, da Escola Nacional de Veterinária, defendeu que essa biotécnica da reprodução deveria ser aplicada de forma rotineira nos rebanhos nacionais (RODRIGUES; RODRIGUES, 2009). Segundo Severo (2015), no ano de 1933, Guilherme Edelberto Hermsdorff, no seu livro Zootecnia Especial, descreveu em 
SILVA, M. A. N.; MELLO, M. R. B.; PALHANO, H. B. Inseminação artificial e inseminação artificial em tempo fixo em bovinos. R. Científica UBM - Barra Mansa (RJ), ano XXVI, v. 23, n. 45, 2 . Sem. 2021 p. 79-97 ISSN 1516-4071

detalhes as diversas fases do método de inseminação artificial na espécie, e ressaltou seu valor econômico.

Dentro desses avanços e melhorias, pode-se citar a combinação da IA com outras biotécnicas como, sincronização do cio e da ovulação, superovulação, transferência de embrião, entre outras. Ao longo dos anos,essa técnica tem se tornado uma importante ferramenta para diversos segmentos da pecuária nacional e tem apresentado tendência de crescimento de forma acelarada. As melhorias e mudanças no seu perfil se devem à necessidade de atender aos padrões internacionais e às exigências de consumidores nacionais (GORDO, 2011).

Nos dias atuais, o espaço para criação extensiva de bovinos tem sofrido concorrência com a agricultura e com a legislação de preservação dos variados biomas nacionais. Com a diminuição da disponibilidade de terras para o exercício da atividade, é necessário o aumento de produtividade, que se caracteriza por maior produção de carne por hectare, abate mais precoce, melhor rendimento de carcaça, maior número de crias por fêmea, e maior produção de leite por lactação, para acompanhar a grande demanda do mercado (GRILLO et al., 2015).

Contextualizando a IA e a IATF, mesmo com todo o crescimento, ainda se tem muito caminho a percorrer, pois de acordo com dados da Associação Brasileira de Inseminação Artificial (ASBIA, 2019), o Brasil insemina apenas 12\% das fêmeas de corte aptas à reprodução e a estimativa para o ano de 2020 era chegar aos $20 \%$ de fêmeas inseminadas, assim, com o passar dos anos, é necessário o avanço das biotécnicas da reprodução como ferramentas do manejo reprodutivo, de forma a aumentar a produtividade e atender às demandas cada vez mais crescentes do Brasil e do mundo.

Com relação à Inseminação Artificial em Tempo fixo, foi somente na década de 90, mais precisamente em 1995, que Pursley et al. (Universidade de Wisconsin, EUA) apresentaram os resultados de trabalhos desenvolvidos com IATF para otimizar a reprodução em fêmeas bovinas leiteiras. Para essa finalidade, foi elaborado um protocolo de manipulação hormonal para sincronização da ovulação envolvendo o hormônio liberador das gonadotrofinas (GnRH) e a prostaglandina (PGF2alfa), formando ambos, a base do primeiro protocolo para IATF, sendo denominado "OvSynch" sendo o primeiro protocolo que possibilitou o uso da IATF com satisfatória taxa de prenhez (PURSLEY et al., 1995).

A motivação para sua criação surgiu do desejo de sincronizar o momento da ovulação de bovinos utilizando GnRH e PGF2alfa, visto que até então as sincronizações eram realizadas apenas com o uso de PGF2alfa. O emprego apenas da prostaglandina apresenta várias limitações: i) o estro não é sincronizado com tanta precisão (variação de 2 a 6 dias) pois os animais podem estar em diferentes momentos do ciclo estral; ii) esse método não dispensa a 
SILVA, M. A. N.; MELLO, M. R. B.; PALHANO, H. B. Inseminação artificial e inseminação artificial em tempo fixo em bovinos. R. Científica UBM - Barra Mansa (RJ), ano XXVI, v. 23, n. 45, 2 . Sem. 2021 p. $79-97$ ISSN 1516-4071

necessidade de observação de cio; iii) exige que os animais estejam ciclando (presença de corpo lúteo). Ficando evidente desta forma, que a utilização de PGF2alfa de forma isolada não apresenta resultados satisfatórios obtendo superioridade em resultados somente quando comparada a sistemas que utilizam apenas detecção de cio diariamente (MAGALHÃES, 2013).

A evolução das pesquisas em sincronização de estro e inseminação em tempo fixo avançam rapidamente e vêm sendo conduzidas em duas direções principais: o método que compreende a utilização de agentes luteolíticos antecipando a regressão do corpo lúteo encurtando o ciclo, e o processo de alongamento da fase lútea pela administração de progesterona ou progestágenos (RODRIGUES et al., 2014; SILVA JR et al., 2014; MONTEIRO Jr. et al., 2015; SILVA et al., 2015; PUGLIESI et al., 2016; YAN et al., 2016; LOIOLA et al., 2018; CARVALHO et al., 2019).

Outro ponto marcante no desenvolvimento das pesquisas com IATF em gado de corte está relacionado ao uso da gonadotrofina coriônica equina (eCG) na composição dos protocolos para a sincronização da ovulação. Estudos relacionados apontam para ganhos significativos em taxa de prenhez na estação de monta de fêmeas zebuínas, sobretudo quando estão em anestro, demonstrando assim a sua viabilidade econômica frente a eficiência reprodutiva proporcionada (SÁ FILHO et al., 2010; SALES et al., 2011; MELLO et al., 2013; MELLO et al., 2014)

Pesquisas na área de fisiologia reprodutiva têm melhorado e refinado os sistemas de IA e de sincronização da ovulação tornando-os mais baratos e eficientes. Hoje, em função de várias pesquisas, existem diversos protocolos envolvendo diferentes associações de hormônios e de manejo que podem ser empregados nos programas de IATF (ALVAREZ, 2008; FURTADO, 2011; MELLO et al., 2014).

Há ainda a possibilidade de associar a IATF com outras ferramentas como os marcadores moleculares, que a partir da análise do DNA permite identificar os animais propensos a maior ganho de peso, fertilidade, resistência a doenças etc (GORDO, 2011).

\subsection{PRINCIPAIS LIMITAÇÕES DA IA CONVENCIONAL}

Mesmo com todas as vantagens da IA em relação ao uso da monta natural (uso de touros testados com ganhos genéticos, melhor controle sanitário, planejamento do manejo reprodutivo e diminuição dos custos de manutenção de touros), a referida biotécnica apresenta algumas limitações, sendo elas expressas principalmente pela falha na detecção de cios, pelo anestro pós-parto (o que significa que para a realização da IA convencional as fêmeas precisam estar ciclando) e pela puberdade tardia (BARUSELLI et al., 2004; TORRES-JÚNIOR et al., 2009). 
SILVA, M. A. N.; MELLO, M. R. B.; PALHANO, H. B. Inseminação artificial e inseminação artificial em tempo fixo em bovinos. R. Científica UBM - Barra Mansa (RJ), ano XXVI, v. 23, n. 45, 2 . Sem. 2021 p. 79-97 ISSN 1516-4071

Em rebanhos Bos taurus indicus, este comprometimento se torna maior, pois esses animais apresentam particularidades no seu comportamento reprodutivo que se caracteriza por cio de curta duração sendo a maior parte desta manifestação durante a noite. Como no Brasil, as fêmeas em reprodução possuem $80 \%$ de sangue zebu, criadas, em sua maioria, a pasto, ocorrem significativos comprometimentos na taxa de detecção de cio e na eficiência dos programas de inseminação artificial convencional (BARUSELLI et al., 2004).

Outro aspecto bastante importante, principalmente em gado de corte, é o anestro pósparto, seja pela perda no escore de condição corporal (ECC) em função de fatores nutricionais, como pelo efeito da mamada observado em zebuínos. Estudos realizados por Whisnant et al. (1986), Vasconcelos et al. (2009) e Oliveira et al. (2010), relatam o efeito negativo da mamada sobre o ciclo estral de vacas de corte, determinando anestro pós-parto em função da inibição da secreção de GnRH por opioides endógenos (encefalinas, endorfinas, dinorfinas) e pela leptina, o que limita o uso da inseminação artificial convencional com observações diárias de cio.

O anestro pós-parto e as falhas na detecção de cio no início da estação de monta em rebanhos comerciais de corte são assim, fatores que contribuem para o prolongamento do período de serviço (MENEGHETTI; VASCONCELOS, 2008; VASCONCELOS et al., 2009), determinando um baixo desempenho reprodutivo dos rebanhos e baixa taxa de desfrute dos mesmos (FERREIRA et al., 2012).

\subsection{VANTAGENS DA IATF SOBRE A IA CONVENCIONAL}

Diversos autores reportam resultados superiores da IATF sobre a IA convencional e Palhano (2008) ainda argumenta que a sincronização da ovulação para realização da inseminação artificial em tempo fixo possibilita que as vacas sejam inseminadas e se tornem gestantes no início da estação de monta (EM), diminuindo o período de serviço, consequentemente o intervalo de partos, o que proporciona o aumento da eficiência reprodutiva do rebanho.

De acordo com Inforzato et al. (2008), a diminuição do IP leva a um maior número de animais nascidos, o que resulta em maior lucratividade.

Uma das maiores vantagens dos protocolos de sincronização da ovulação é a eliminação da necessidade de observação de cio, o que aumenta a proporção de vacas prenhas no fim da estação de monta (NOGUEIRA, 2017). Por eliminar a necessidade de observação de cio e concentrar os nascimentos em épocas pré-determinadas, o uso da IATF também otimiza e concentra o tempo de mão de obra, melhorando a qualidade de vida dos funcionários das propriedades, além de diminuir o número de horas extras com inseminadores (GORDO, 2011). 
SILVA, M. A. N.; MELLO, M. R. B.; PALHANO, H. B. Inseminação artificial e inseminação artificial em tempo fixo em bovinos. R. Científica UBM - Barra Mansa (RJ), ano XXVI, v. 23, n. 45, 2 . Sem. 2021 p. 79-97 ISSN 1516-4071

Ainda segundo Amaral et al. (2003), com a sincronização da ovulação, há a possibilidade da diminuição dos custos com a mão de obra por causa da diminuição do tempo gasto com inseminação e observação de cio, isso é considerado um fator positivo na discussão sobre o custo/benefício da IATF.

Em gado de corte, o uso de IATF sem observação de cio pós-protocolo, só deve ser instituído ao se estabelecer um manejo de repasse com touro após a inseminação no protocolo, pois assim, os touros serão responsáveis por detectarem cio e pela cobertura das fêmeas que não emprenharam no manejo de IATF, ou ainda, em manejo de IATF com ressincronização após diagnóstico de gestação precoce, via ultrassonografia.

Com relação aos custos, a viabilidade econômica da IATF ainda tem sido muito discutida e, segundo Gordo (2011), a maior limitação atribuída a essa técnica está relacionada à viabilidade econômica, pois, em algumas situações, o custo/benefício pode não ser favorável. Entretanto, Magalhães (2013) aponta a diferença de custo dos protocolos como devida aos hormônios utilizados nos protocolos para sincronização de estro, porém, ao avaliar o custo por prenhez, a diferença de preço cai significativamente, pois, como já dito, com o uso da IATF, as taxas de prenhez são maiores, quando comparadas àquelas observadas na IA convencional. Ainda em relação aos custos, Amaral et al. (2003) demonstraram que a eficiência reprodutiva alcançada com a IATF reduz o custo por prenhez, entretanto, os autores citam que isso não é o suficiente para tornar os programas de IATF mais atrativos que a IA convencional, a não ser que esta possua baixa taxa de prenhez, em torno de $50 \%$.

Gottschall e Silva (2014) avaliaram o desembolso individual e o custo por prenhez de diferentes protocolos para IATF, em novilhas de corte, comparando os protocolos Ovsynch modificado, Heat Synch, também modificado e um terceiro protocolo elaborado com base em benzoato de estradiol (BE), progesterona e prostaglandina. Os resultados mostraram que o desempenho econômico da IATF é fortemente influenciado pela resposta biológica dos animais. A melhor taxa de prenhez tornou o protocolo de maior desembolso individual (Ovsynch modificado) o protocolo mais atraente economicamente, uma vez que o custo da gestação foi bem inferior aos demais grupos.

Vasconcelos (2006) argumenta que a viabilidade do custo da IATF por vaca depende das variáveis vaca, sêmen, inseminador e protocolo, de forma que as vacas com melhor condição corporal apresentam maior taxa de concepção e um menor custo por vaca gestante. Da mesma forma, vacas com menor condição corporal resultam em menor taxa de concepção e em um maior custo. De acordo com o autor, a qualidade do sêmen e do inseminador também tem que ser considerada, pois, qualquer falha diminui a concepção, com aumento do custo por 
SILVA, M. A. N.; MELLO, M. R. B.; PALHANO, H. B. Inseminação artificial e inseminação artificial em tempo fixo em bovinos. R. Científica UBM - Barra Mansa (RJ), ano XXVI, v. 23, n. 45, 2 . Sem. 2021 p. 79-97 ISSN 1516-4071

vaca gestante. Logo, a ocorrência de falha, em qualquer uma dessas variáveis, proporciona um resultado menor que o esperado.

Visando à melhoria da relação custo/benefício dos programas de IATF, alguns dispositivos de progesterona permitem sua reutilização, configurando-se como uma alternativa interessante para redução de custos dos protocolos que utilizam esses dispositivos (ALMEIDA et al., 2006; CARVALHO et al., 2019).

Outra vantagem da IATF é a possibilidade de inseminar muitos animais em um mesmo dia, permitindo a obtenção de um grande número de animais gestantes nos primeiros 10 dias da estação de monta em gado de corte e, como exemplo, cita-se o tempo médio gasto para inseminar uma vaca e esse tempo permite calcular a possibilidade de inseminar 180 animais em 6 horas, contudo, deve-se levar em conta a habilidade do inseminador além de seu cansaço físico (INFORZATO et al., 2008).

Diante do exposto, nota-se que a IATF apresenta inúmeras vantagens sobre a IA convencional, como por exemplo, aumento da taxa de serviço, concentração do trabalho em dias pré-determinados, possibilidade de planejamento de partos e da estação de monta subsequente, concentração e planejamento da desmama de bezerros, planejamento na reposição de matrizes, aumento da produção em bovinos de leite, diminuição do desperdício de sêmen, material e mão de obra, alta taxa de prenhez no início da estação de monta melhorando a distribuição da prenhez em gado de corte, diminuição do descarte e custo de reposição das matrizes do rebanho, potencialização da viabilidade de uso da IA, entre outras.

A escolha entre IATF e a IA convencional (com observação de cios), depende das taxas de prenhez e da eficiência na detecção de cio (recomenda-se IATF em propriedades em que a taxa de detecção de cio seja inferior a 50\%) e para que seu uso seja efetivamente viável é necessário a avaliação do custo/benefício ao escolher um protocolo de IATF.

A escolha do melhor protocolo depende de uma avaliação técnica das condições dos animais que serão inseminados. Se bem aplicada, a IATF traz como principal resultado o aumento da taxa de desfrute, ou seja, o aumento da produtividade (PALHANO et al., 2011; FURTADO et al., 2011; GORDO, 2011; FERREIRA, 2012; NOGUEIRA, 2017)

\subsection{APLICAÇÕES DA IATF EM GADO DE LEITE}

Nos dez anos anteriores a 2012, a produção nacional de leite cresceu 10,7 bilhões de litros, com destaque para um crescimento médio na produtividade das vacas ordenhadas da ordem de 2,1\% ao ano (RESENDE; STOCK, 2014). 
SILVA, M. A. N.; MELLO, M. R. B.; PALHANO, H. B. Inseminação artificial e inseminação artificial em tempo fixo em bovinos. R. Científica UBM - Barra Mansa (RJ), ano XXVI, v. 23, n. 45, 2 . Sem. 2021 p. 79-97 ISSN 1516-4071

A viabilidade econômica da produção leiteira é decisiva para o crescimento e manutenção dos produtores dentro desta atividade, sendo essa viabilidade o resultado de diversos fatores que em sua maioria dependem do controle e manejo a que esses animais são submetidos. A eficiência reprodutiva é um desses determinantes para o sucesso da atividade e depende de animais saudáveis e potencialmente produtivos. No caso de bovinos leiteiros, a produção de leite é a principal fonte de renda, e essa produção está ligada à parição, tendo-se como principal objetivo alcançar a máxima produção diária de leite por vaca a um mínimo custo alimentar. Para isso, faz-se necessário que as vacas produzam bezerros em intervalos regulares, devendo ser inseminadas e tornarem-se gestantes dentro de um período de tempo restrito, obedecendo a sua fisiologia. Se essa concepção for atrasada, a ineficiência reprodutiva pode levar a uma diminuição da produção de leite, comprometendo a atividade (PASQUALOTTO et al., 2015).

De acordo com Sartori et al. (2002), o aumento da produção de leite está associado à redução da eficiência reprodutiva de vacas leiteiras, observando-se uma relação inversamente proporcional, concluindo-se que vacas com maior produção leiteira possuem menor taxa de prenhez, quando comparadas a vacas de menor produção leiteira, o que pode ser explicado pelo intenso metabolismo orgânico com dietas de alta densidade e grandes volumes de ingestão.

Com o intuito de aumentar as taxas de serviço e a eficiência reprodutiva, foram desenvolvidos programas hormonais de sincronização, utilizando prostaglandina. Porém, mesmo com o uso de programas hormonais, as taxas de concepção de vacas leiteiras continuam baixas (TEIXEIRA, 2010). É sabido que vacas de alta produção possuem elevado consumo de matéria seca, o que provoca alterações em seu metabolismo.

Sangsritavong et al. (2002) explicam que este fato pode estar associado às altas taxas de metabolismo dos esteroides no fígado. De acordo com Sartori et al. (2002), isto gera menores níveis circulantes de estradiol e progesterona (P4) quando comparados com animas não lactantes. Sendo assim, uma forma de minimizar esse efeito é a indução do aumento da produção de progesterona pelo corpo lúteo para minimizar a elevada taxa de metabolização desse hormônio pelo fígado em vacas de alta produção (TEIXEIRA, 2010).

É nesse contexto que se insere a aplicação da IATF em gado de leite. Baruselli et al. (2004) incorporaram a gonadotropina coriônica equina em protocolos de IATF e notaram um aumento na fertilidade. Os autores argumentam que a hipótese da melhora na taxa de prenhez nos animais que receberam eCG na retirada do dispositivo intravaginal de $\mathrm{P} 4$ está relacionada ao aumento da taxa de ovulação de animais em anestro e aos maiores níveis de P4 circulante no diestro. 
SILVA, M. A. N.; MELLO, M. R. B.; PALHANO, H. B. Inseminação artificial e inseminação artificial em tempo fixo em bovinos. R. Científica UBM - Barra Mansa (RJ), ano XXVI, v. 23, n. 45, 2 . Sem. 2021 p. 79-97 ISSN 1516-4071

Souza (2015) observou, em seu experimento, que o tratamento com progesterona em fêmeas de alta produção da raça Holandesa, inseminadas em tempo fixo, foi positivo para taxa de concepção aos 30 dias.

Segundo Teixeira (2010), a utilização do protocolo de sincronização da ovulação para IATF, em vacas de alta produção de leite, antecipa a primeira inseminação no período pós-parto sem que haja comprometimento da taxa de concepção em todos os períodos do ano, além disso, grupos submetidos à IATF apresentam menor intervalo parto-concepção. Da mesma forma, Silenciato et al. (2016) concluíram que as variações climáticas durante o ano não interferiram na eficiência dos protocolos de IATF e que a inclusão da progesterona no protocolo melhorou taxas de concepção e de prenhez.

A melhora na eficiência reprodutiva das vacas de leite de alta produção é fator de grande importância para o sucesso da atividade, assim, a utilização de protocolos hormonais para IATF pode aumentar a taxa de serviço e antecipar a primeira inseminação no período pós-parto, o que proporciona menor intervalo parto-concepção, contudo, para que o emprego da técnica em vacas leiteiras seja bem sucedido, é necessário rigor quanto as recomendações das doses, momento das aplicações e qualidade dos produtos utilizados nos protocolos de sincronização (TEIXEIRA, 2010).

\subsection{APLICAÇÕES DA IATF EM GADO DE CORTE}

De acordo com Nogueira (2017), as exigências do mercado e dos consumidores, por produtos de qualidade e segurança, fazem os produtores na pecuária de corte buscarem, cada vez mais, estratégias tecnológicas e de manejo para garantir maior retorno econômico da atividade.

Ao se intencionar maior retorno econômico, pensa-se em eficiência reprodutiva e, segundo Ferraz et al. (2008), esta é o aspecto mais importante dentro de um sistema de produção de bovinos de corte, pois ela está diretamente relacionada ao aumento na taxa de desfrute do rebanho. Ainda segundo os autores, muitos pecuaristas amargam grandes perdas econômicas quando suas matrizes não produzem o número de bezerros desejado.

Segundo Godoi et al. (2010), mesmo sendo detentor do maior rebanho de gado de corte comercial do mundo, o Brasil ainda apresenta produção e reprodução com baixos índices zootécnicos.

Cunha (2011) cita, como consequência do sistema de criação onde os animais recebem com máxima intensidade os efeitos do clima, a queda na qualidade reprodutiva, mesmo que 
SILVA, M. A. N.; MELLO, M. R. B.; PALHANO, H. B. Inseminação artificial e inseminação artificial em tempo fixo em bovinos. R. Científica UBM - Barra Mansa (RJ), ano XXVI, v. 23, n. 45, 2 . Sem. 2021 p. 79-97 ISSN 1516-4071

esse rebanho apresente tolerância às condições do ambiente tropical, sendo necessária a busca de metas associadas ao aumento da eficiência reprodutiva e à elevação dos índices de produção.

Inforzato et al. (2008) concordam com os autores acima citados quando dizem que, independente do sistema de criação, vacas de corte têm sérios problemas em relação à eficiência reprodutiva, e que esse é um dos principais fatores de influência no sucesso econômico da atividade. Nesse cenário, a utilização das biotécnicas da reprodução, como a IATF, promove melhoras na produtividade do rebanho nacional, e consequente aumento na possibilidade de se atingir as demandas impostas pelo mercado (CUNHA, 2011).

Assim, a inseminação artificial se tornou uma das principais biotécnicas reprodutivas com impacto econômico na produção de bovinos, possibilitando o melhoramento genético do plantel, através de cruzamentos industriais em regiões tropicais, aumentando a produção de carne por hectare (FURTADO et al., 2011).

Dias et al. (2016) verificaram que houve desempenho superior do grupo F1 de bezerros oriundos de cruzamento industrial entre as raças Nelore e Aberdeen Angus, por meio de inseminação artificial, e esses bezerros obtiveram diferenças significativas no peso ao nascer, peso ajustado aos 205 dias, peso ao desmame e ganho de peso diário quando comparados a bezerros exclusivamente da raça Nelore, demonstrando que existem mais vantagens na utilização de tecnologias que permitem o cruzamento industrial, como a IA ou IATF.

Por meio do melhoramento genético- proporcionado pela técnica de inseminação, baseado na seleção de indivíduos com características que se deseja obter no rebanho de corte, como, maior desenvolvimento ponderal, rendimento de carcaça, melhor conversão alimentar e precocidade sexual- pode-se alcançar aumento de produtividade (INFORZATO et al., 2008). Ainda no campo de melhoramento genético, Nogueira (2017) cita o critério de seleção na velocidade de crescimento em determinadas idades como sendo um critério utilizado no intuito de obter animais precoces, o que é muito desejado na bovinocultura de corte ao proporcionar diminuição do tempo de permanência dos animais no rebanho, favorecendo a lucratividade do sistema, através de um retorno mais ágil do capital investido.

Em relação ao estro, sabe-se que em rebanhos brasileiros, principalmente naqueles destinados à produção de carne, há predominância de animais Bos taurus indicus. Segundo Baruselli et al. (2004), a maioria das fêmeas em reprodução possui 80\% de sangue zebu criadas em sua maioria, a pasto, e o estro desses animais é mais curto em relação aos animais Bos taurus taurus, o que dificulta a detecção de estro, principalmente se esses animas forem criados em regime extensivo, como acontece na maioria dos rebanhos de corte brasileiros e a maior parte 
SILVA, M. A. N.; MELLO, M. R. B.; PALHANO, H. B. Inseminação artificial e inseminação artificial em tempo fixo em bovinos. R. Científica UBM - Barra Mansa (RJ), ano XXVI, v. 23, n. 45, 2 . Sem. 2021 p. 79-97 ISSN 1516-4071

desta manifestação ocorre durante a noite, o que prejudica ainda mais a detecção eficiente do estro.

Outra questão a ser levada em consideração na implantação da IA ou IATF, consiste na condição corporal das fêmeas contextualizadas nos programas, visto que a deficiência nutricional pode impactar negativamente na taxa de prenhez como demonstrado por Ferreira et al. (2013), ao avaliarem o impacto da condição corporal sobre a taxa de prenhez de vacas da raça Nelore, sob regime de pasto em programa de inseminação artificial em tempo fixo. No estudo em questão, os autores concluíram que as fêmeas de pior condição corporal (ECC $\leq$ 2,5), apresentaram menor taxa de prenhez quando comparadas aquelas de melhor condição $(\mathrm{ECC} \geq 3)$ quando submetidas a um programa de IATF.

Uma outra técnica, avaliada por Souza et al. (2015), foi o desmame temporário por 48 horas, aliado ou não a protocolos de IATF, como uma ferramenta de manejo reprodutivo ao proporcionar melhoras na taxa de prenhez quando o manejo permite a sua implantação.

No que diz respeito às fêmeas primíparas, categoria com menores taxas de prenhez, na estação de monta, em rebanhos sob manejo extensivo, Cunha (2011) conclui que a utilização de inseminação artificial em tempo fixo- no início da estação de monta, em vacas primíparas lactantes de corte, em diferentes fases de desenvolvimento folicular -foi efetiva na melhoria de taxas ovulatórias e gestacionais, gerando redução de anestro pós-parto, período de serviço e intervalo pós-parto, quando comparadas à animais submetidos apenas à monta natural. Nogueira (2017) relata que os valores fenotípicos e genéticos, estudados em seu trabalho, apresentaram-se superiores no grupo de animais obtidos por meio de IATF, garantindo retorno econômico da atividade.

Uma outra opção de manejo, relacionada à IATF, que vem crescendo muito em gado de corte é a ressincronização (ressinc). Esta técnica consiste no emprego do protocolo de IATF, associado ao diagnóstico precoce de gestação e à subsequente ressincronização das fêmeas vazias, ou seja, é a repetição do protocolo de IATF nas fêmeas que não emprenharam na primeira IATF (SÁ FILHO et al., 2014). Dentre as vantagens da ressincronização, estão a maximização do número de fêmeas gestantes de inseminação no início da estação de monta e a possibilidade de reduzir o número de reprodutores necessários ao repasse após a ressincronização.

Atualmente, existem três modelos de ressincronização: i) ressinc tradicional (D30) no qual, o diagnóstico de gestação é realizado com ultrassom modo B, 30 dias pós-inseminação, e nas fêmeas vazias inicia-se um novo protocolo de IATF; ii) ressinc precoce (D22) no qual, no $22^{\circ}$ dia pós-inseminação (antes do diagnóstico de gestação com ultrassom modo B), inicia-se 
SILVA, M. A. N.; MELLO, M. R. B.; PALHANO, H. B. Inseminação artificial e inseminação artificial em tempo fixo em bovinos. R. Científica UBM - Barra Mansa (RJ), ano XXVI, v. 23, n. 45, 2 . Sem. 2021 p. 79-97 ISSN 1516-4071

novo protocolo de IATF em todas as fêmeas mas no $30^{\circ}$ dia pós-IA, apenas as fêmeas diagnósticadas como vazias pelo ultrassom receberão prostaglandina e serão inseminadas; iii) ressinc superprecoce (D14) no qual, 14 dias pós-inseminação, inicia-se novo protocolo de IATF e no $22^{\circ}$ dia pós-IA, com auxílio da ultrassonografia Doppler e diagnóstico de gestação via perfusão vascular do corpo lúteo, somente as fêmeas vazias seguem no tratamento e são inseminadas. Como exemplo do sucesso da ressincronização em gado de corte, Marques et al. (2015) obtiveram taxa de prenhez geral por IATF de 81\% (1985/2464) em fêmeas Nelores aos 40 dias de estação de monta, sendo 85\% (770/903) nas novilhas, 76\% (257/338) nas primíparas e 78\% (958/1223) nas multíparas. No estudo destes autores, a concepção geral à primeira IATF foi de 55\% (1367/2464) e a segunda IATF (ressinc) foi realizada após diagnóstico gestacional ultrassonográfico (30 dias pós IATF) com taxa de concepção de 56\% (618/1097).

\section{CONSIDERAÇÕES FINAIS}

Atualmente, diversos estudos avaliam protocolos para realização da IATF os quais permitem o controle do desenvolvimento folicular e da ovulação em bovinos de corte, auxiliando no aumento da eficiência reprodutiva dos animais. A IA convencional também possui o seu espaço como ferramenta de manejo reprodutivo, principalmente no contexto da IATF, como parte dessa biotécnica ou como repasse, de acordo com o planejamento e decisão do técnico inserido na assistência aos mais variados modelos de exploração pecuária e suas diretrizes de manejo reprodutivo.

Nesse contexto de manejo reprodutivo, tanto a IA convencional como a IATF representam ferramentas em que o planejamento e avaliação dos resultados devem estar norteados por uma organização técnica eficiente na seleção dos animais; decisão de qual técnica e em que momento utilizá-la, aplicação correta de hormônios, escolha do protocolo a ser utilizado, sêmen, descongelamento do sêmen, manejo geral do rebanho e capacitação de recursos humanos envolvidos com todo o processo. Vale ressaltar a importância do produtor dispor de pastagens de boa qualidade, fornecer sal mineral e água de boa qualidade e à vontade, e o imprescindível planejamento, execução e monitoramento sanitário para que o rebanho responda de forma eficiente à biotécnica utilizada. Em função da baixa utilização da IA convencional e da IATF, quando se analisa o total do rebanho bovino brasileiro, a assistência técnica qualificada possui um papel preponderante para a expansão do uso das mesmas e consequentemente para o aumento de produtividade por meio do melhoramento genético em bovinocultura de leite e corte. 
SILVA, M. A. N.; MELLO, M. R. B.; PALHANO, H. B. Inseminação artificial e inseminação artificial em tempo fixo em bovinos. R. Científica UBM - Barra Mansa (RJ), ano XXVI, v. 23, n. 45, 2 . Sem. 2021 p. 79-97 ISSN 1516-4071

Portanto, conclui-se que o emprego da IATF traz diferenças significativas nos parâmetros produtivos, facilitando o manejo e aumentando a eficiência da IA no rebanho, entretanto, a viabilidade econômica da IATF depende da observação da condição corporal das vacas, sêmen de fertilidade comprovada, equipe estimulada e treinada, e da realização de um repasse da sincronização.

\section{REFERÊNCIAS}

ALMEIDA, A. B.; BERTAN, C. M.; ROSSA, L. A. F.; GASPAR, P. S.; BINELLI, M.; MADUREIRA, E. H. Avaliação da reutilização de implantes auriculares contendo norgestomet associados ao valerato ou ao benzoato de estradiol em vacas Nelore inseminadas em tempo fixo. Brazilian Journal of Veterinary Research and Animal Science, v.43, n.4, p.456-465, 2006.

ALVAREZ, R. H. Considerações sobre o uso da inseminação artificial em bovinos. http://www.infobibos.com/Artigos/2008_1/Inseminacao/index.htm, 2008. Acesso em outubro 2019.

AMARAL, T. B.; COSTA, F. P.; CORRÊA, E. S. Touros melhoradores ou inseminação artificial: um exercício de avaliação econômica. Embrapa Gado de Corte, 2003.

ASBIA. Artigos 2019 - Inseminação Artificial. Disponível em :http://www.asbia.org.br/artigos/inseminacao-artificial/. Acesso em Setembro 2019.

BARUSELLI, P. S.; REIS, E. L.; MARQUES, M. O.; NASSER, L. F.; BÓ, G. A. The use of hormonal treatments to improve reproductive performance of anestrous beef cattle in tropical climates. Animal Reproduction Science, v.82-83, p.479-486, 2004.

CARVAlHO, J. S.; CAVAlCANTI, M. O.; CHAVES, M. S.; RIZZO, H. Eficiência da inseminação artificial em tempo fixo em fêmeas zebuínas na mesorregião Sudeste do Para, Brasil. Amazonian Journal of Agricultural and Environmental Sciences. v.62, p.1-7, 2019.

CUNHA, R. R. Inseminação artificial em tempo fixo em primíparas Nelore lactantes acíclicas. 2011. 44p. Dissertação (Mestrado em Medicina Veterinária) - Universidade José do Rosário Vellano, Minas Gerais, 2011.

DIAS, L. L. R.; ORLANDINI, C. F.; STEINER, D.; MARTINS, W. D. C.; BOSCARATO, A. G.; ALBERTON, L. R. Ganho de peso e características de carcaça de bovinos Nelore e meio sangue Angus-Nelore em regime de suplementação a pasto. Arquivos de Ciências Veterinárias e Zoologia da UNIPAR, v.18, n.3, 2016.

FERRAZ, H. T.; VIU, M. A. O.; LOPES, D. T.; OLIVEIRA FILHO, B. D.; GAMBARINI, M. L. Sincronização da ovulação para realização da inseminação artificial em tempo fixo em bovinos de corte. PUBVET, v.2, n.12, 2008.

FERREIRA, M. C. N.; MIRANDA, R.; ABIDU-FIGUEIREDO, M.; PALHANO, H. B. Avaliação da taxa de gestação em vacas nelore multíparas submetidas à inseminação artificial 
SILVA, M. A. N.; MELLO, M. R. B.; PALHANO, H. B. Inseminação artificial e inseminação artificial em tempo fixo em bovinos. R. Científica UBM - Barra Mansa (RJ), ano XXVI, v. 23, n. 45, 2 . Sem. 2021 p. $79-97$ ISSN 1516-4071

e inseminação artificial em tempo fixo. Revista Brasileira de Medicina Veterinária, v.34, n.2, p.152-156, 2012.

FERREIRA, M. C. N.; MIRANDA, R.; ABIDU FIGUEIREDO, M; COSTA, O. M.; PALHANO, H. B. Impacto da condição corporal sobre a taxa de prenhez de vacas da raça nelore sob regime de pasto em programa de inseminação artificial em tempo fixo (IATF). Semina: Ciências Agrárias, v.34, n.4, p. 1861-1868, 2013.

FURTADO, D. A.; TOZZETTI, D. S.; AVANZA, M. F. B.; DIAS, L. G. G. G. Inseminação artificial em tempo fixo em bovinos de corte. Revista Científica Eletrônica de Medicina Veterinária, v.16, p.1-25, 2011.

GODOI, C. R.; SILVA, E. F. P.; DE PAULA, A. P. Inseminação artificial em tempo fixo (IATF) em bovinos de corte. PUBVET, v.4, p.802-808, 2010.

GORDO, J. M. L. Análise da situação da inseminação artificial bovina no estado de Goiás. 2011. 91f. Tese (Doutorado em Zootecnia) - Universidade Federal de Goiás, Goiânia, 2011.

GOTTSCHALL, C. S.; SILVA, L. R. Análise econômica de diferentes protocolos para inseminação artificial em tempo fixo (IATF) aplicados em novilhas de corte. Veterinária em Foco, v11, n.2, p.119-125, 2014.

GRILlO, G. F.; GUIMARÃES, A. L. L.; SOARES, J. R.; MELLO, M. R. B.; SILVA AFONSO, L.; FIGUEIREDO, M. A.; PALHANO, H. B. Efeito da triagem ginecológica sobre as taxas de concepção e gestação total de vacas Nelore submetidas a três protocolos de inseminação artificial em tempo fixo (IATF). Brazilian Journal of Veterinary Medicine, v.37, n.3, p.250-254, 2015.

IBGE. "Indicadores IBGE - Estatística da Produção Pecuária". 2019. Disponível em: ftp://ftp.ibge.gov.br/Producao_Pecuaria/Fasciculo_Indicadores_IBGE/abate-leite-couroovos_201801caderno.pdf

IBGE. "Indicadores IBGE - Estatística da Produção Pecuária". 2016. Disponível em: ftp://ftp.ibge.gov.br/Producao_Pecuaria/Fasciculo_Indicadores_IBGE/abate-leite-couroovos 201801caderno.pdf

INFORZATTO, G. R.; SANTOS, W. D.; CliMENI, B. S. O.; DELlALIBERA, F. L.; FILADELPHO, A. L. Emprego de IATF (Inseminação Artificial em Tempo Fixo) como alternativa na reprodução da pecuária de corte. Revista Científica Eletrônica de Medicina Veterinária, v.11, p.1-8, 2008.

LOIOLA, M. V. G.; BITTENCOURT, R. F.; RODRIGUES, A. S.; FERRAZ, P. A.; LIMA, M. C. C.; CARVALHO, C. V. D.; RIBEIRO FILHO, A. L. Oral progesterone supplementation for beef cattle after insemination in TAI programs. Pesquisa Agropecuária Brasileira, v.53, n.1, p.105-112, 2018.

MAGALHÃES, P. C. M. Estratégias para adoção da inseminação artificial em vacas zebuínas. 2013. 54f. Dissertação (Mestrado) - Universidade José do Rosário Vellano, Alfenas, 2013. 
MARQUES, M. O.; MOROTTI, F.; SILVA, C. B.; JÚNIOR, M. R.; SILVA, R. C. P.; BARUSELLI, P. S.; SENEDA, M. M. Influence of category-heifers, primiparous and multiparous lactating cows-in a large-scale resynchronization fixed-time artificial insemination program. Journal of Veterinary Science, v.16, n.3, p.367-371, 2015.

MELlO, R. R. C.; MELlO, M. R. B.; FERREIRA, J. E.; SILVA, A. P. T. B.; MASCARENHAS, L. M.; SILVA, B. J. F.; CARDOSO, B. O.; PALHANO, H. B. Reproductive parameters of Sindhi cows (Bos taurus indicus) treated with two ovulation synchronization protocols. Revista Brasileira de Zootecnia, v.42, p.414-420, 2013.

MELLO, R. R. C.; FERREIRA, J. E.; MELLO, M. R. B.; PALHANO, H. B. Utilização da gonadotrofina coriônica equina (eCG) em protocolos de sincronização da ovulação para IATF em bovinos: revisão. Revista Brasileira de Reprodução Animal, v.38, n.3 p.129-134, 2014.

MENEGHETTI, M.; VASCONCELOS, J. L. M. Calving date, body condition score, and response to a timed artificial insemination protocol in first-calving beef cows. Arquivo Brasileiro de Medicina Veterinária e Zootecnia, v.60, n.4, p.786-793, 2008.

MONTEIRO JÚNIOR, P. L. J.; NASCIMENTO, A. B.; PONTES, G. C. S.; FERNANDES, G. O.; MELO, L. F.; WILTBANK, M. C.; SARTORI, R. Progesterone supplementation after ovulation: effects on corpus luteum function and on fertility of dairy cows subjected to AI or ET. Theriogenology, v.84, p.1215-1224, 2015.

NOGUEIRA, C. S. Impacto da IATF (inseminação artificial em tempo fixo) sobre características de importância econômica em bovinos Nelore. 2017. 44f. Dissertação (Mestrado em Zootecnia) - Faculdade de Ciências Agrárias e Veterinárias- UNESP, Jaboticabal, 2017.

OLIVEIRA, J. F. C.; GONÇALVES, P. B. D.; FERREIRA, R.; GASPERIN, B.; SIQUEIRA, L. C. Controle sobre GnRH durante o anestro pós-parto em bovinos. Ciência Rural, v.40, n.12, p.2623-2631, 2010.

PALHANO, H. B.; JESUS, V. L. T.; ABIDU-FIGUEIREDO, M.; BALDRIGHI, J. M.; MELLO, M. R. B. Efeito da ciclicidade de vacas nelore sobre as taxas de concepção e de prenhez após protocolos de sincronização para inseminação artificial em tempo fixo. Brazilian Journal of Veterinary Medicine, v.34, n.1, p.63-68, 2012.

PALHANO, H. B. Reprodução em Bovinos: Fisiopatologia, Terapêutica, Manejo e Biotecnologia. 2. ed. Rio de Janeiro: L. F. Livros, 2008

PASQUALOTTO, W.; SEHNEM, S.; WINCK, C. A. Incidência de rinotraqueíte infecciosa bovina (IBR) diarréia viral bovina (BVD) e leptospirose em bovinos leiteiros da região Oeste de Santa Catarina-Brasil. Revista em Agronegócio e Meio Ambiente, v.8, n.2, p.249, 2015.

PUGLIESI, G.; SANTOS, F. B.; LOPES, E.; NOGUEIRA, É.; MAIO, J. R. G.; BINELLI, M. Improved fertility in suckled beef cows ovulating large follicles or supplemented with longacting progesterone after timed-AI. Theriogenology, v.85, p.1239-1248, 2016.

PURSLEY, J. R.; WILTBANK, M. C.; MEE, M. C. Synchronization of ovulation in dairy cattle using PGF and GnRH. Theriogenology, v.44, n.7, p.915-923, 1995. 
SILVA, M. A. N.; MELLO, M. R. B.; PALHANO, H. B. Inseminação artificial e inseminação artificial em tempo fixo em bovinos. R. Científica UBM - Barra Mansa (RJ), ano XXVI, v. 23, n. 45, 2 . Sem. 2021 p. $79-97$ ISSN 1516-4071

RESENDE, J. C.; STOCK, L. A. Crescimento e mudanças geográficas da produção de leite no Brasil entre 2002 e 2012. Boletim CBLeite, $n^{\circ}$ 20. Embrapa Gado de Leite. Juiz de Fora: 2014.

RODRIGUES, J. L; ÁVILA RODRIGUES, B. Evolução da biotecnologia da reprodução no Brasil e seu papel no melhoramento genético. Ceres, v.56, n.4, p. 428-436, 2009.

RODRIGUES, M. C.; LEÃO, K. M.; SILVA, N. C.; SILVA, R. P.; VIU, M. A. O.; CARDOSO, L. M. Administração de acetato de melengestrol após inseminação artificial em tempo fixo em vacas Nelore lactantes. Revista Brasileira de Saúde e Produção Animal, v.15, p.361-368, 2014.

SÁ FILHO, M. F.; AYRES, H.; FERREIRA, R. M.; MARQUES, M. O.; REIS, E. L.; SILVA, R. C.; RODRIGUES, C. A.; MADUREIRA, E. H.; BÓ, G. A.; BARUSELLI, P. S. Equine chorionic gonadotropin and gonadotropin-releasing hormone enhance fertility in a norgestomet-based, timed artificial insemination protocol in suckled Nellore (Bos indicus) cows. Theriogenology, v.73, p.651-658, 2010.

SÁ FILHO, M. F.; MARQUES, M. O.; GIROTTO, R.; SANTOS, F. A.; SALA, R. V.; BARBUIO, J. P.; BARUSELLI, P. S. Resynchronization with unknown pregnancy status using progestinbased timed artificial insemination protocol in beef cattle. Theriogenology, v. 81, p.284-290, 2014.

SALES, J. N. S.; CREPALDI, G. A.; GIROTTO, R. W.; SOUZA, A. H.; BARUSELLI P. S. Fixed-time AI protocols replacing eCG with a single dose of FSH were less effective in stimulating follicular growth, ovulation, and fertility in suckled-anestrus Nellore beef cows. Animal Reproduction Science, v.124, p.12-18, 2011.

SANGSRITAVONG, S.; COMBS, D. K.; SARTORI, R.; ARMENTANO, L. E.; WILTBANK, M. C. High feed intake increases liver blood flow and metabolism of progesterone and estradiol$17 \beta$ in dairy cattle. Journal of Dairy Science, v.85, n.11, p.2831-2842, 2002.

SARTORI, R.; ROSA, G. J. M.; WILTBANK, M. C. Ovarian structures and circulating steroids in heifers and lactating cows in summer and lactating and dry cows in winter. Journal of Dairy Science, v.85, n.11, p.2813-2822, 2002.

SEVERO, N. C. História da inseminação artificial no Brasil. Revista Brasileira Reprodução Animal, v.39, n.1, p.17-21, 2015.

SILENCIATO, L. N.; MELLO, M. R. B.; ANDRADE, R. B.; JÚNIOR, F. C. D.; NETO, J. B. R.; CAVALCANTE, M. C.; PALHANO, H. B. Eficiência de dois protocolos de IATF em vacas leiteiras mestiças em diferentes estações do ano. Brazilian Journal of Veterinary Medicine, v.38, n.Supl.2, p.169-174, 2016.

SILVA, R. P.; LEÃO, K. M.; RODRIGUES, M. C.; MARQUES, T. C.; SILVA, N. C.; VIU, M. A. O. Aplicação de GnRH no dia da inseminação artificial em tempo fixo (IATF) e administração de acetato de melengestrol (MGA) após IATF em vacas nelore solteiras. Semina: Ciências Agrárias, v.36, p.3149-3160, 2015. 
SILVA JUNIOR, L. S.; FREIRIA, L. B.; ANGREVESSILVA, G. M.; POSSAMAI, A. J.; HATAMOTO-ZERVOUDAKIS, L. K.; SILVA, M. R. Uso do acetato de melengestrol após protocolos de inseminação artificial em tempo fixo em vacas Nelore multíparas. Revista Brasileira de Saúde e Produção Animal, v.15, p.425-429, 2014.

SOUZA, E. D. F. Efeito da progesterona injetável de longa ação na função luteínica e na taxa de concepção de vacas Holandesas de alta produção submetidas à IATF . 2015. 68f. Dissertação (Mestrado) - Universidade de São Paulo, São Paulo, 2015.

SOUZA, A. L. B.; KOZICKI, L. E.; PEREIRA, J. F. S.; SEGUI, M. S.; WEISS, R. R.; BERTOL, M. A. F. Eficiência da gonadotrofina coriônica equina (eCG) e do desmame temporário (DT) em protocolos para inseminação artificial em tempo fixo (IATF) em vacas nelore previamente tratadas com progesterona (P4) e benzoato de estradiol (BE). Archives of Veterinary Science, v.20, n.1, p.22-29, 2015.

TEIXEIRA, A. A. Impacto da inseminação artificial em tempo fixo na eficiência reprodutiva de vacas de leite de alta produção. 2010. 60f. Dissertação (Mestrado) - Universidade de São Paulo, São Paulo, 2010.

TORRES-JÚNIOR, J. R. S.; MELO, W. O.; ELIAS, A. K. S.; RODRIGUES, L. S.; PENTEADO, L.; BARUSELLI, P. S. Considerações técnicas e econômicas sobre reprodução assistida em gado de corte. Revista Brasileira de Reprodução Animal. v.33, n.1, p.53-58, 2009.

VASCONCELOS, J. L. M. Inseminação em tempo fixo. AgroAnalysis, v.26, n.7, p.27, 2006.

VASCONCELOS, J. L. M.; VILELA, E. R.; SÁ FILHO, O. G. Remoção temporária de bezerros em dois momentos do protocolo de sincronização da ovulação GnRH-PGF2 $\alpha$-BE em vacas Nelore pós-parto. Arquivo Brasileiro de Medicina Veterinária e Zootecnia, v.61, n.1, p.95-103, 2009.

WHISNANT, C. S.; KISER, T. E.; THOMPSON, F. N. Opioid inhibition of luteinizing hormone secretion during the postpartum period in suckled beef cows. Journal of Animal Science, v.63, n.5, p.1445-1448, 1986.

YAN, L.; ROBINSON, R.; SHI, Z.; MANN, G. Efficacy of progesterone supplementation during early pregnancy in cows: a meta-analysis. Theriogenology, v.85, p.1390-1398, 2016. 